\title{
Measuring the health burden of chronic disease and injury using health adjusted life expectancy and the Health Utilities Index
}

\author{
D G Manuel, S E Schultz, J A Kopec
}

J Epidemiol Community Health 2002;56:843-850

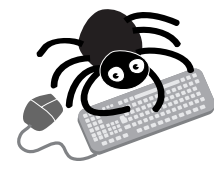

Additional information relating to this paper is available on the journal web site (www.jech.com) See end of article for authors' affiliations

......................

Correspondence to: Dr D Manuel, Institute for Clinical Evaluative Sciences, G-1 19, 2075 Bayview Avenue, Toronto, Ontario, Canada M4N $3 \mathrm{M5}$;

d.manuel@utoronto.ca

Accepted for publication 4 February 2002

\begin{abstract}
Objectives: To estimate the burden of illness from chronic disease and injury using a population based health survey, which contains both measures of chronic disease and a utility based health related quality of life (HRQOL) measure.

Design: An adapted Sullivan method was used to calculate cause deleted health adjusted life expectancies for chronic conditions.

Setting: Ontario, Canada, 1996/97.

Subjects: The 1996/97 Ontario Health Survey ( $n=35$ 527) was used to estimate the prevalence of chronic conditions. A cause deleted approach was used to estimate the impact of these conditions on the Health Utilities Index (HUI). Cause deleted probabilities of dying were derived with the cause eliminated life table technique and death data from vital statistics for Ontario 1996/97 ( $\mathrm{n=156} 610$ ).

Results: Eliminating cardiovascular disease and cancer will cause an "expansion of morbidity", while eliminating mental conditions and musculosketal disorders will result in a "contraction of morbidity". The HUI score varies depending on chronic condition, age, and sex-most of which were assumed not to vary in previous summary measures of population health.

Conclusions: Health adjusted life expectancy estimated for chronic conditions using a utility based measure of health related quality of life from population health surveys addresses several limitations of previous studies that estimate the burden of disease using either a categorical measure of disability or expert opinion and related epidemiological evidence.
\end{abstract}

$\mathrm{E}$ fforts to develop measures of population health that take into account both mortality and morbidity have resulted in the development of two major classes of summary measures of population health (SMPH): positive measures of health expectancy, ${ }^{12}$ such as health adjusted life expectancy (HALE), and measures of health gaps such as healthy life years ${ }^{3}$ or disability adjusted life years (DALYs). ${ }^{4}$ In the case of health expectancy, which is the focus of this study, estimates of overall life expectancy or life years lived are adjusted according to the amount of time spent in less than perfect health or with disability.

Health expectancy measures were initially calculated for populations as a whole. More recently, SMPH have been used to estimate the burden of illness from specific conditions and diseases and, following from this, the expected gains from their reduction or elimination..$^{3-7}$ The population health impact of a specific condition or group of conditions depends on a number of interrelated factors: the death rate from the condition, its prevalence, its effect on health related quality of life (HRQOL), and the age of the population affected by the condition. Thus, generating summary measure estimates for specific conditions or diseases presents the added challenge of not only defining and measuring HRQOL but also estimating the prevalence (or incidence) of a condition and properly attributing decrements in HRQOL to that specific condition.

There have been two main approaches to estimating disease specific or condition specific incidence/prevalence and HRQOL for use with SMPH. The World Health Organisation's Global Burden of Disease (GBD) project, for example, uses observational epidemiological evidence and expert opinion to estimate the incidence of different conditions and the degree of disability (their measure of HRQOL) associated with each one, which in turn are used to calculate DALYs. ${ }^{48}$ The original GBD project assigned one disability weight per condition, but a recent adaptation in the Netherlands expanded on this and identified different levels of severity for each condition.'

The second approach uses the results of population based health surveys, which often contain information about the presence of chronic conditions and diseases as well as a number of different measures of HRQOL, to estimate both the HRQOL associated with a disease or condition and its prevalence. As such surveys often contain a number of different HRQOL indicators, this approach has led to the development of a variety of health expectancy measures, distinguishable primarily by the measure of HRQOL used. ${ }^{1}$ The most widespread of these is some measure of disability, yielding estimates of either disability free life expectancy (DFLE), when the disability measure is dichotomous, or health adjusted life expectancy (HALE), when the disability measure has different levels that are then combined into a single value using utility weights that are specific for each level of disability. Mathers calculated HALE by assigning utility values to several discrete disability levels. ${ }^{6}$

The two approaches differ in several important ways. One advantage of the GBD method is that it has been designed for

Abbreviations: HUI; Health Utilities Index; HRQOL, health related quality of life; SMPH, summary measures of population health; HALE, health adjusted life expectancy; DALY, disability adjusted life year; DFLE, disability free life expectancy 
use in a variety of countries with very different levels of data availability. However, its reliance on expert opinion for the development of the weights used for each condition requires assumptions (frequently untested) to be made about the relation between the condition and other factors such as age, sex, and interactions with other conditions. By contrast, using population based health surveys, which often contain information not only about the condition of interest, but other factors as well, means that these possible confounders can be controlled for with fewer assumptions. The result is a potentially more accurate measure of the actual burden of illness or disability from the condition of interest. Population surveys also often include utility based measures of HRQOL. ${ }^{10}{ }^{11}$ In utility based measures, weights are assigned to each health state that lies between perfect health (1.0) and death $(0.0)$, or even states worse than death $(<0.0) .{ }^{12}$ Population based utility measures are particularly attractive to health economists and other health planners as they can more appropriately be compared with mortality and/or disease specific utility based measures. ${ }^{13}$ Also, as utility based measures of HRQOL often use polychotomous weights, they are also more sensitive to differences in severity within a population.

In this study we have used the information from such a study to estimate the burden of disease in Ontario, Canada from a number of different conditions using the Health Utilities Index, a utility based measure of HRQOL, to estimate cause deleted HALE. To the best of our knowledge, this represents the first time utility based measures have been used to estimate cause specific HALE for a variety of chronic conditions. The method used herein represents a potential improvement over previous summary measures of population health, including the utility based approaches of Mathers and the GBD DALYs, because it reduces the need to make assumptions about the relation between the condition of interest and other factors such as age, sex, severity, and the presence of other conditions.

\section{METHODS \\ Data sources}

Cross sectional data on health status and chronic conditions were derived from the 1996/97 Ontario Health Survey (OHS II). ${ }^{14}$ The Ontario Ministry of Health sponsored Statistics Canada to augment the Ontario sample of the 1996/97 National Population Health Survey to enable the production of local level estimates. Briefly, 48770 households were selected through a stratified, multilevel cluster sampling method of all private dwellings in Ontario, with local planning regions as the primary sampling unit. Residents of Indian reserves, long term institutions, Foreign Service personnel, and remote areas were excluded. There were two components to the interview, which was conducted by telephone, virtually all households in Ontario have telephones. The general component collected limited information on all members of the household; household response rate was $77.5 \%$, or 37796 households. The second component, which is the component used in this study, was administered to one randomly selected member from each survey household. The number of non-child respondents was 35 527, a response rate of $94.0 \%$.

Statistics Canada mortality files from 1996 and 1997 were used to calculate the age specific and sex specific death rates for Ontario. In total 156610 Ontario residents died during the study period. Post-censal population estimates for 1996/97 for age group and sex group were from Statistics Canada.

\section{Variable definition and classification Disease/condition groups}

Information about chronic conditions was obtained in two ways in the OHS II. Survey respondents were asked specifically if they had ever been diagnosed with any of 20 conditions. As well, those who reported long term activity restriction were asked in an open ended question to give a "main cause" for their restriction. Reported conditions were grouped according to the classifications listed in appendix 1. In most cases these correspond to chapter headings from 9th Revision of the International Classification of Disease (ICD-9). ${ }^{15}$ The exceptions to this are as follows: circulatory system disorders were divided into ischaemic/other heart disease and other circulatory disorders; diabetes was considered on its own; cancer does not include benign neoplasms; and deaths from suicide were included with mental disorders rather than accidents and injuries. Two further points of note: injuries were reported as a cause of activity restriction, but were not part of the list of 20 chronic conditions. Thus, our HRQOL estimates are only for injuries severe enough to cause activity restriction. Secondly, mental disorders were not on the list of chronic conditions, but were instead defined from the mental health section of the survey. Respondents were considered to have a mental condition if responses to a depression index indicated a $90 \%$ probability of a major depressive disorder. ${ }^{16}$ No information was available for other mental disorders such as bipolar disorder or schizophrenia. Mortality rates were available by ICD-9 code only (including the E-codes for injuries and poisonings). These were classified according to column 2 of appendix 1 .

\section{The Health Utilities Index}

The HRQOL measure used to calculate HALE in this study was the Health Utilities Index (HUI). ${ }^{17}$ The HUI is a utility based, multi-attribute health classification system that estimates a summary value of individual health where $0.0=$ "dead" and $1.0=$ "perfect health", (states worse than death are also possible), based on preference scores for different health states. ${ }^{18}$ Each respondent answers questions pertaining to eight attributes of functional health: vision, hearing, speech, mobility, dexterity, emotional state, cognition, and level of pain and discomfort. In the version used in this study, vision, hearing, and speech are combined into one sensory attribute. Each attribute has from four to six possible levels ranging from unrestricted to a highly disabled state (see appendix 2 (available on the journal web site (www.jech.com) or Torrance et $a l^{19}$ for a description of health states). These are then combined using the following multi-attribute utility function where $\mathrm{U}=$ the overall HUI score and $\mathrm{Ul}$ to $\mathrm{U} 6$ are the attribute specific utility score:

$$
u=1.06\left(u_{1} \times u_{2} \times u_{3} \times u_{4} \times u_{5} \times u_{6}\right)-0.06
$$

The preference score for each attribute and the subsequent multi-attribute preference function was derived from an earlier (Mark II) version. ${ }^{19}$ A provisional conversion scoring system was used to apply Mark II weights to the Mark III questions that were used in this study.

\section{Analysis methods}

\section{Calculation of mortality and prevalence rates}

Age-sex specific mortality rates for the various disease/ condition groups were calculated using mortality data and post-censal population estimates from Statistics Canada.

Prevalence rates were estimated using a method intended to mirror the system used for deaths such that, wherever feasible, only one chronic condition/cause of morbidity was allowed. This was relatively straightforward for those who reported long term activity restriction or those who had no activity restriction and reported only one chronic condition. In the former case, the reported "main cause of activity restriction" was the only condition included, in the latter, the single chronic condition. For those who did not report long term activity restriction but reported more than one chronic condition, it was impossible to make assumptions about which condition to include and which to exclude, so this group was permitted to have multiple conditions, and the 


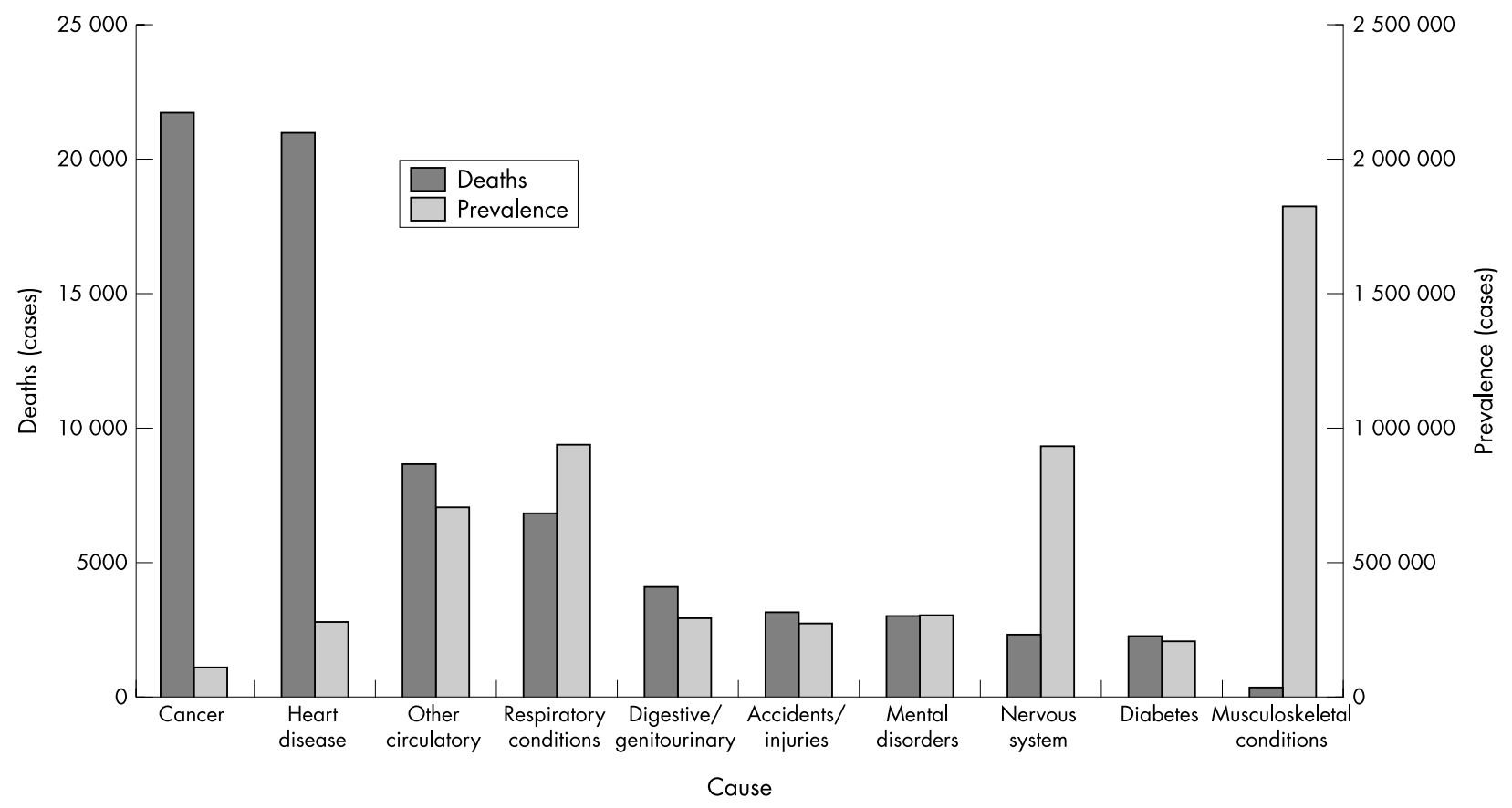

Figure 1 Number of deaths and prevalence, chronic conditions, Ontario 1996/97. Total population 11.3 million.

independent effect of each was estimated using linear regression modelling.

Cause deleted mortality rate and HUI estimates Cause deleted mortality rates were calculated by subtracting the cause specific mortality rates from the overall mortality rate for each age sex group.

Calculating cause deleted mean HUI estimates entailed several steps. As mentioned above with respect to prevalence estimates, our sample was divided into two groups: those with a single cause of morbidity; and those who were permitted multiple morbidity because they had no activity restriction but reported more than one chronic condition. The method of calculating cause deleted HUI estimates for the former group was quite straightforward-as the term "cause deleted" suggests, those with each cause were removed from the population and the mean HUI estimates were recalculated for the remaining respondents. This methodology is based on the assumption that when a particular disease or condition is removed from the population, the pattern of morbidity and mortality in those without the disease/condition generalises to the entire population (see equation 1 , appendix 3 ). ${ }^{620}$

For the second group, those with no reported long term activity restriction but two or more chronic conditions, it was necessary to control for comorbidity, which was done using linear regression modelling. All conditions were included in the model, and separate models were run for each 10 year age sex group, generating regression coefficients for the independent effect of having each condition. These regression coefficients for each condition/disease were then used in equation 2 , appendix 3, to calculate the cause deleted mean HUIs for this subsample. Finally, the estimates from the two groups were combined (see equation 3, appendix 3 ) to yield overall cause deleted mean HUI estimates for each disease/condition.

\section{Life table analysis}

Period life tables for 1996/97 for men and women were calculated using an adaptation of Chiang's method and 20 standard age groups $(<1,1-4,5-9, \ldots, 90+$ years $) .{ }^{21}$ Cause deleted life expectancy was calculated by substituting the cause deleted mortality rates for the overall mortality rates in the life table. ${ }^{22}$
HALE was calculated using a modified Sullivan method. ${ }^{23}$ This prevalence based life table technique weights the years of life lived according to a measure of health status, in this case, the HUI. HALE was calculated using the mean HUI values for the population as a whole. Then the cause deleted mean HUI values were used to calculate cause deleted HALE. The change in HALE after eliminating a disease or cause of disability is interpreted as the impact of that particular disease or condition and the burden of disease it represents.

\section{RESULTS}

Figure 1 shows the number of deaths and estimated prevalence (cases) for the various conditions in Ontario in 1996/97 (total population 11.3 million). As expected, cancer and heart disease are responsible for the greatest number of deaths, although the number of prevalent cases is quite low. At the other end of the spectrum, musculoskeletal disorders such as arthritis and back pain have the highest number of cases, but result in few deaths. If one were to consider only the number of people affected by a condition, musculoskeletal conditions would have the greatest population health impact.

The effect of a condition on HRQOL varies from one condition to another (table 1). For example, Ontario men reporting disabling injuries had a mean HUI of 0.77, while for those with respiratory disorders it was 0.94. A comparison of the unadjusted and age adjusted mean HUI estimates reveals two observations: that age has an independent effect on the HUI, and that age alone is not sufficient to explain the differences in mean HUI between conditions, leading one to conclude that disease factors must play a part as well.

Table 1 and figure 1 provide illustrations of the separate mortality and morbidity burdens associated with each condition. To estimate the overall burden of illness from each condition in a way that combines both mortality and morbidity, the cause deleted methodology outlined above was used. The resulting estimates of life expectancy and HALE are listed in table 2. Current life expectancy for men and women in Ontario is 76.2 and 81.4 years respectively, while HALE is estimated to be 70.5 for men and 74.1 for women. Cancer currently represents the greatest burden of disease in the population, and eliminating it would increase men's life expectancy to 79.7 
Table 1 Mean HUl by condition and sex, adjusted and unadjusted

\begin{tabular}{|c|c|c|c|c|}
\hline Condition & Sex & $\begin{array}{l}\text { Number } \\
\text { (unwtd) }\end{array}$ & $\begin{array}{l}\text { Mean HUI } \\
\text { (unadjusted) }\end{array}$ & $\begin{array}{l}\text { Mean HUI (age } \\
\text { adjusted*) }\end{array}$ \\
\hline \multirow[t]{2}{*}{ Heart disease } & $\mathrm{F}$ & 633 & 0.873 & 0.902 \\
\hline & M & 700 & 0.863 & 0.897 \\
\hline \multirow[t]{2}{*}{ Other circulatory disorders } & $\mathrm{F}$ & 1813 & 0.895 & 0.901 \\
\hline & $M$ & 1343 & 0.897 & 0.923 \\
\hline \multirow[t]{2}{*}{ Cancer } & $\mathrm{F}$ & 301 & 0.875 & 0.906 \\
\hline & M & 213 & 0.863 & 0.910 \\
\hline \multirow[t]{2}{*}{ Diabetes } & $\mathrm{F}$ & 454 & 0.896 & 0.926 \\
\hline & $M$ & 448 & 0.893 & 0.933 \\
\hline \multirow[t]{2}{*}{ Respiratory disorders } & $\mathrm{F}$ & 2478 & 0.920 & 0.920 \\
\hline & M & 1503 & 0.939 & 0.929 \\
\hline \multirow[t]{2}{*}{ Muscoskeletal disorders } & $\mathrm{F}$ & 5157 & 0.863 & 0.879 \\
\hline & M & 3101 & 0.891 & 0.903 \\
\hline \multirow[t]{2}{*}{ Mental disorders } & $\mathrm{F}$ & 862 & 0.865 & 0.850 \\
\hline & $M$ & 428 & 0.863 & 0.846 \\
\hline \multirow[t]{2}{*}{ Injuries } & $\mathrm{F}$ & 588 & 0.749 & 0.765 \\
\hline & M & 705 & 0.770 & 0.790 \\
\hline \multirow[t]{2}{*}{ Digestive/genitourinary } & $\mathrm{F}$ & 828 & 0.893 & 0.903 \\
\hline & M & 514 & 0.891 & 0.907 \\
\hline \multirow[t]{2}{*}{ Nervous system and sense organs } & $\mathrm{F}$ & 2761 & 0.895 & 0.902 \\
\hline & $M$ & 1191 & 0.885 & 0.898 \\
\hline \multirow[t]{2}{*}{ All others } & $\mathrm{F}$ & 5690 & 0.927 & 0.925 \\
\hline & M & 3608 & 0.942 & 0.937 \\
\hline \multirow[t]{2}{*}{ All conditions } & $\mathrm{F}$ & 13566 & 0.891 & 0.891 \\
\hline & M & 9984 & 0.905 & 0.905 \\
\hline
\end{tabular}

Table 2 Cause deleted life and health expectancy by disease group and sex

\begin{tabular}{|c|c|c|c|c|}
\hline \multirow[b]{2}{*}{ Disease group (cause) eliminated } & \multicolumn{2}{|c|}{$\begin{array}{l}\text { Cause deleted Life expectancy } \\
\text { (LE) (years) }\end{array}$} & \multicolumn{2}{|c|}{$\begin{array}{l}\text { Cause deleted Health Adjusted } \\
\text { Life Expectancy (HALE) (years) }\end{array}$} \\
\hline & Male & Female & Male & Female \\
\hline Overall (no cause eliminated) & 76.2 & 81.4 & 70.5 & 74.1 \\
\hline Cancer & 79.7 & 84.9 & 73.4 & 77.0 \\
\hline Heart disease & 79.3 & 84.2 & 73.1 & 76.1 \\
\hline Musculoskeletal & 76.2 & 81.5 & 70.9 & 75.2 \\
\hline Other circulatory & 77.1 & 82.6 & 71.2 & 75.0 \\
\hline Injuries & 76.9 & 81.9 & 71.5 & 74.8 \\
\hline Respiratory & 77.0 & 82.2 & 71.2 & 74.7 \\
\hline Nervous system/sense organs & 76.4 & 81.8 & 70.8 & 74.6 \\
\hline Digestive/genitourinary & 76.7 & 81.9 & 70.9 & 74.5 \\
\hline Mental disorders & 76.7 & 81.8 & 71.0 & 74.5 \\
\hline Diabetes & 76.5 & 81.7 & 70.7 & 74.3 \\
\hline All others & 77.4 & 82.4 & 72.2 & 75.6 \\
\hline
\end{tabular}

from 76.2 years and women's from 81.4 to 84.9 years. HALE would rise to 77 years for women and 73.4 years for men. Eliminating heart disease has a similar effect on life expectancy, but results in smaller gains in HALE compared with cancer.

In figure 2, the gains in life expectancy and HALE from the elimination of the various conditions are compared. This figure also provides a useful illustration of what is known as the compression or expansion of morbidity. ${ }^{24}$ Expansion of morbidity occurs when the proportion of life spent in less than good health increases. In figure 2 expansion of morbidity is evident when the years of HALE gained are less than the years of life expectancy gained, as in the case of cancer and heart disease. Compression of morbidity refers to a situation where the proportion of life in less than perfect health decreases, or when the HALE gained is greater than the life expectancy gained. This is clearly the case with musculoskeletal conditions and also for injuries. In the case of musculoskeletal, the gain in life expectancy if these conditions were eliminated would be very small, but there would be an overall gain in HALE of more than a year for women and about half a year for men.

\section{DISCUSSION}

The objective of the study was to use cause deleted HALE to estimate the burden of disease from a number of conditions, 


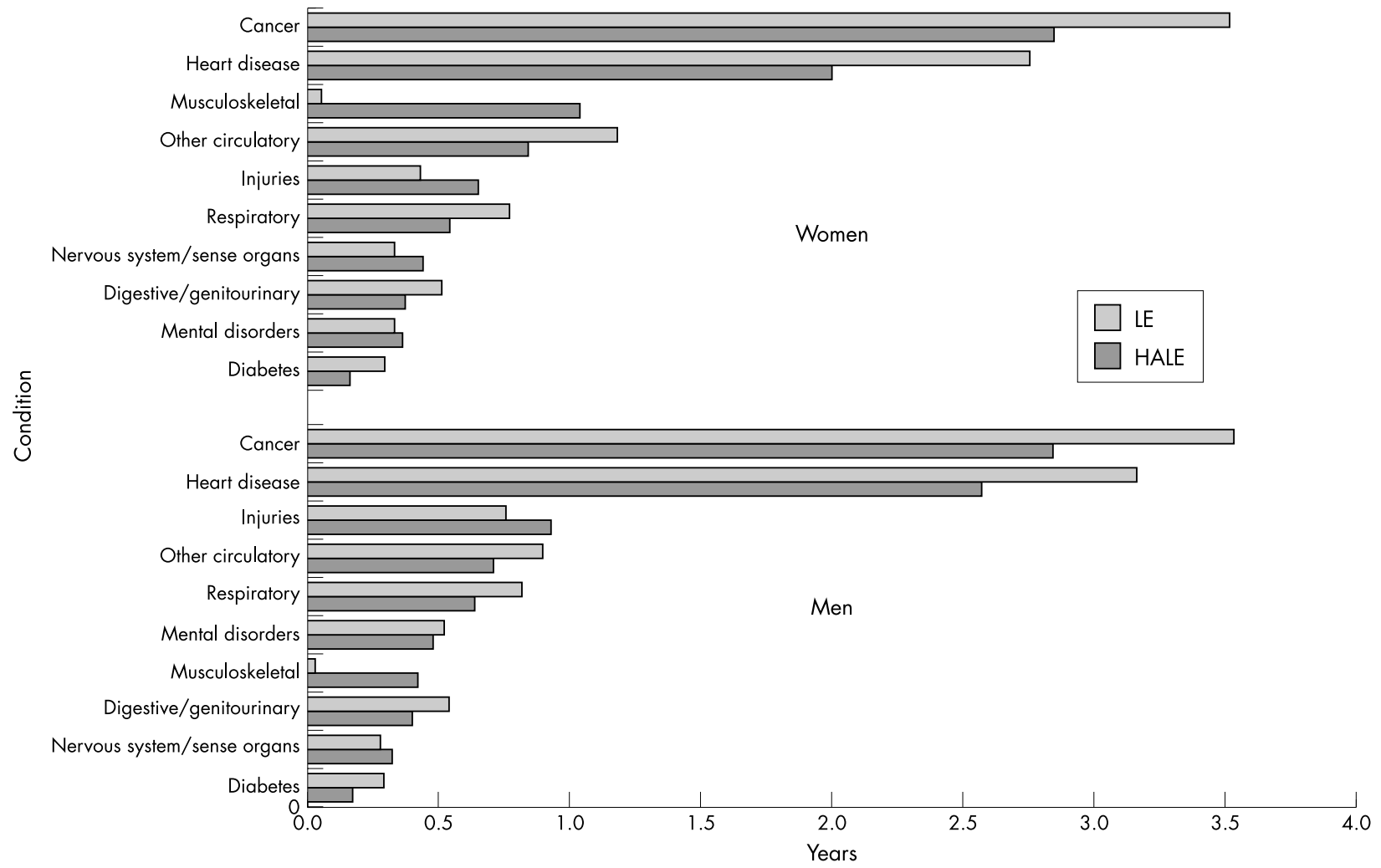

Figure 2 Gains in life expectance (LE) and health adjusted life expectancy (HALE) after eliminating conditions, Ontario.

through the use of a general population health survey, which contained questions on both a utility based health status index and the presence of chronic conditions. Similar to previous studies, ${ }^{35-725}$ heart disease and cancer have the greatest impact on HALE because of their high death rates. The loss of life expectancy from cancer, for example, is 3.5 years for both men and women. However, eliminating cancer would result in an expansion of morbidity, as one fifth of the years of life expectancy gained would be spent in poor health. Eliminating musculoskeletal conditions, on the other hand, would result in a compression of morbidity, as there would be only a small gain in life expectancy, but a gain of more than a year of good health for women and nearly half a year for men.

Until recently most calculations of health expectancy for specific conditions have used discrete health states ${ }^{3-7} 25$; 2 ; of which the most popular measure has been a dichotomous valuation of disability where health status is assigned a value of zero until a threshold, beyond which the valuation is one. Such dichotomous valuations make the measure sensitive to variation in the threshold definition, potentially creating obstacles when classifying disability in different conditions. Nusselder et al speculated that their disability cut off may have contributed to their small estimated contribution of cancer on morbidity. ${ }^{5}$

Mathers combined several levels of disability into a single utility weight to estimate HALE, thereby overcoming the limitation of a single measure and allowing HRQOL to be directly valued against mortality. ${ }^{6}$ However, his weights were not adjusted for age, sex, or the presence of comorbidity. The changes in the HUI after adjusting for age suggest not only that there is an age effect, but also that it differs across conditions. This being the case, a polychotomous index like the HUI for different conditions and ages and sex may more accurately assess a utility value of HRQOL.

While Mathers' method was an improvement over the dichotomous measure based DFLE, people with chronic conditions were only included if they had either impairment, disability, or handicap. In this study, HRQOL estimates were available for the entire population, not just those with disability that, again, should result in improved accuracy in estimating the impact of each condition within the population.

An issue of particular concern when measuring disease specific HRQOL is comorbidity. The GBD DALY estimates are not controlled for comorbidity, and indeed this adjustment would be difficult using present methods. As the use of population based health surveys that elicit information about the presence of multiple conditions has become common, researchers have been able to control for these conditions in their estimates of HRQOL; however, the methodology used in many studies, particularly those using dichotomous measures of disability, assumes that eliminating a condition results in a non-disabled state (perfect health) regardless of age. ${ }^{5} 672530$ Because we had available both a polychotomous index and information about the presence of multiple conditions we had the option of control for comorbidity in several ways. Firstly, our condition specific HRQOL estimates are partially adjusted for other conditions. Secondly, our method does not assume that eliminating a condition results in perfect health. Instead, it assumes that the HRQOL of those whose disease has been eliminated would be equal to the mean HRQOL for the age-sex matched population without the condition, many of whom are not in perfect health-even if they did not report a disability (see fig 1)-because of a variety of factors. Thus, the potential gain in HRQOL may be less for persons in their older years than for those who are younger, because the average older person has a lower HRQOL.

Health gap measures such as DALYs generally use incidence based measures of HRQOL impact, as compared with the prevalence based methods that are most commonly used in health expectancy measures. Comparisons of these measures have been discussed in detail elsewhere ${ }^{426}$ but there are several considerations worth highlighting in the context of our study. Population based health surveys are useful for estimating the long term consequences of eliminating diseases in different populations as they directly estimate the health status 


\section{Key points}

- The Health Utilities Index (HUI) is a survey based health measure that incorporates several health domains ex pressed in one utility value between 0 and 1 .

- To estimate the health burden of chronic diseases data are needed on the disease prevalence and its impact on health related quality of life and mortality.

- Using the HUI as the HRQOL measure, eliminating cardiovascular disease and cancer will cause an "expansion of morbidity" while eliminating mental conditions and musculoskeletal disorders will result in a "compression of morbidity"

- Compared with previous methods, using a survey based utility measure of $\mathrm{HRQOL}$ reduces the number of assumptions about the relations between $\mathrm{HRQOL}$ and age, sex, illness severity, and comorbidity.

of a population at a defined time period. These estimations of cause specific health status are the combined effect of disease incidence, duration, and severity. As health gap measures, such as the common estimation of DALYs, often require different sources of information for each of these disease properties they may have difficulty reflecting differences in the health status impact of diseases in varying populations and time periods. In particular, the present derivation of DALYs uses the same disability weights for different ages and sexes; whereas prevalence based health surveys use HRQOL that may vary based on these factors. For an example of these differences consider what would happen to HRQOL burden of arthritis if a new medication that dramatically improved pain and mobility was widely introduced into a population for the treatment of older arthritis patients. A population based health survey would capture this current improvement. DALYs, as commonly derived, would require further epidemiological studies and expert opinion to readjust disability weights to assess the health impact of this intervention. Without adjusting disability weights for different ages, the DALY method may not appropriately adjust for the HQROL effect of the medication introduction in older people. As there are many factors affecting disease burden (that is, socioeconomic conditions, physical and social environment, medical therapies, health risk behaviour) in different populations it would seem improbable that the current DALY approach could reflect the actual disease burden in any one population.

An additional benefit of population based general health surveys is the ability to combine measures of health status with other survey responses to estimate HALE based on socioeconomic status or other health attributes such as pain, mobility, dexterity. ${ }^{28}$ In turn, these studies could be combined with cause deleted HALE to examine the combined effect of socioeconomic status and chronic conditions.

There are several drawbacks when estimating chronic condition prevalence from health surveys. Reliance on respondents' self report in health interviews containing either an open-ended question or a checklist of chronic conditions may bias results. Compared with medical examinations and disease registries, self report of chronic conditions is often linked to factors such as the severity of illness and the need for medical treatment. ${ }^{31-34}$ Thus, conditions not requiring treatment are less likely to be reported. Similarly, there is probably an underestimation of the contribution of acute conditions to overall health status as questions on specific causes of these conditions is often lacking in general population health surveys. Disability from acute diseases is often thought to be a greater concern in developing countries but even in developed countries upper respiratory tract infections have been shown to be the largest cause of disability days. ${ }^{35}$ A characteristic of the OHS II and other population based surveys not previously mentioned is the ability to validate or improve the definition of diseases by directly linking survey respondents to their health care utilisation (laboratory tests, drug prescriptions filled, hospital discharge diagnosis, physician visit diagnosis, etc) and to disease registries. The use of health administrative databases to define the prevalence or incidence of a disease in a population is becoming increasing common in health services research, ${ }^{36}$ disease registries, ${ }^{37}$ and health gap measures. ${ }^{38}$

Finally, incidence based and prevalence based indicators measure different things - and which is more appropriate to use depends on the application. For instance, incidence based indicators are generally regarded as monitoring the trends of disease occurrence and, therefore, disease prevention and future health. A subsection of respondents in the health survey used in this analysis continue to be followed up over time as part of the Canadian National Population Health Survey. With the addition of disease incidence and health status transition information this survey has been used to create hybrid indicators that combine the principles of both prevalence based and incidence based indicators. ${ }^{26} 2739$

Population health surveys with a utility based health status index should be regarded as a valuable component of population health surveillance as they can describe the incremental differences in health status between disease groups with few a priori assumptions of the relation with age, sex, or level of severity. As such these surveys are well suited to answer what is the health status of a population for selected conditions-a product of all the health influences of that disease from health promotion to palliation. The greatest limitation of health surveys for this purpose is the inherent difficulty in estimating disease prevalence based on self report. For this reason it may be helpful to regard population health surveys not as isolated data sources, but as part of an integrated health status surveillance system that includes health administrative data, disease registries, and a longitudinal follow up component. Together these data sources could provide robust information on present and future disease and health status transitions for summary measures of population health.

\section{Authors' affiliations}

D G Manuel, S E Schultz, J A Kopec, Institute for Clinical Evaluative Sciences, Toronto, Canada

D G Manuel, J A Kopec, Department of Public Health Sciences,

University of Toronto, Canada

J A Kopec, University of British Columbia, Vancouver, Canada

Funding: Dr Manuel is a supported in part by a Career Scientist Award, Ontario Ministry of Health, Dr Kopec is supported in part by an Investigator Award, Canadian Institute for Health Research.

Conflicts of interest: none.

\section{REFERENCES}

1 Mathers C, Robine J-M, eds. Health expectancy indicators: a review of the work of REVES to date. London: John Libbey, 1993

2 Robine JM, Romieu I, Cambois E. Health expectancy indicators. Bull World Health Organ 1999;77:181-5.

3 Hyder AA, Rotllant G, Morrow RH. Measuring the burden of disease: healthy life-years. Am J Public Health 1998;88:196-202.

4 Murray C, Lopez AD, eds. The global burden of disease: a comprehensive assessment of mortality and disability from diseases, injuries, and risk factors in 1990 and projected to 2020. Cambridge, MA: Published by the Harvard School of Public Health on behalf of the World Health Organisation and the World Bank; distributed by Harvard University Press; 1996

5 Nusselder WJ, van der Velden K, van Sonsbeek JL, et al. The elimination of selected chronic diseases in a population: the compression and expansion of morbidity. Am J Public Health 1996;86:187-94.

6 Mathers CD. Gains in health expectancy from the elimination of diseases among older people. Disabil Rehabil 1999;21:211-21.

7 Picavet HS, van den Bos GA. The contribution of six chronic conditions to the total burden of mobility disability in the Dutch population. Am J Public Health 1997;87: 1680-2.

8 World Health Organisation. World Health Report 2000 Health Systems: improving performance. Geneva: WHO, 2000. 
9 Melse JM, Essink-Bot ML, Kramers PG et al. A national burden of disease calculation: Dutch disability-adjusted life-years. Dutch Burden of Disease Group. Am J Public Health 2000;90:1241-7.

$10 \mathrm{McD}$ owell I. Measuring health a guide to rating scales and questionnaires. 2nd edn. New York: Oxford University Press, 1996.

11 Bowling A. Measuring health a review of quality of life measurement scales. 2nd edn. Buckingham: Open University Press, 1997:xi, 159

12 Torrance GW, Feeny D. Utilities and quality-adjusted life years. Int $J$ Technol Assess Health Care 1989;5:559-75.

13 Ferguson BM, Keown PA. An introduction to utility measurement in health care. Infect Control Hosp Epidemiol 1995;16:240-7.

14 Statistics Canada. 1996 NPHS Public Use Microdata Documentation. Ottawa: Statistics Canada, 1999.

15 ICD-9-CM International classification of diseases, 9th revision, clinical. In: DHHS publication. Washington, DC: US Department of Health and Human Services Public Health, 1988.

16 Diverty B, Beaudet M. Depression: an undertreated disorder? Health Reports 1997;8:9-18

17 Feeny D, Torrance G, Furlong W. Health Utilities Index. In: Spilder B, ed. Quality of life and pharmacoeconomics in clinical trials. 2nd edn. Philadelphia: Lippincott-Raven, 1996.

18 Feeny D, Furlong W, Boyle $M$, et al. Multi-attribute health status classification systems. PharmacoEconomics 1995;7:490-502

19 Torrance G, Furlong W, Feeny D, et al. Multi-attribute preference functions - health utilities index. PharmocoEconomics 1995;7:503-20.

20 Muennig PA, Gold MR. Using the years-of-healthy-life measure to calculate QALYs. Am J Prev Med 2001;20:35-9.

21 Chiang CL. The life table and its applications. Malabar, FL: Robert E Krieger, 1984

22 Newman S. Formulae for cause-deleted life tables. Stat Med 1987;6:527-8.

23 Sullivan D. A single index of mortality and morbidity. HSMHA Health Reports 1971;86:347-54

24 Fries J. The compression of morbidity. Milbank Memorial Fund Quarterly/Health and Society 1983:61:397-419.

25 Mathers CD. Estimating the gains in health expectancy due to the elimination of specific diseases. In: Fifth meeting of the International Network on Health Expectancy (REVES-5). Ottawa: Statistics Canada, 1992.

26 Murray C, Salomon J, Mathers C. A critical examination of summary measures of health. Geneva: WHO, 1999.
27 Barendregt JJ. Incidence- and prevalence-based summary measures of population health: making the twain meet. Geneva: WHO, 1999. 28 Wolfson M. Health-adjusted life expectancy. Health Reports 1996:8:41-5.

29 Manton KG Stallard E. Cross-sectional estimates of active life expectancy for the US elderly and oldest-old populations. J Gerontol 1991;46:S170-82.

30 Bonneaux L, Barendregt J, Nusselder W, et al. Preventing fatal diseases increases health care costs: cause elimination life table approach. BM 1998:316:26-9.

31 Heliovaara $M$, Aromaa A, Klaukka T, et al. Reliability and validity of interview data on chronic diseases. The Mini-Finland Health Survey. J Clin Epidemiol 1993;46:181-91.

32 Beckett $M$, Weinstein $M$, Goldman $N$, et al. Do health interview surveys yield reliable data on chronic illness among older respondents? Am J Epidemiol 2000;151:315-23.

33 Gross R, Bentur N, Elhayany A, et al. The validity of self-reports on chronic disease: characteristics of underreporters and implications for the planning of services. Public Health Rev 1996;24:167-82.

34 Jabine TB. Reporting chronic conditions in the National Health Interview Survey. A review of findings from evaluation studies and methodological test. Vital Health Stat 2 1987; $1-45$

35 Péron $Y$, Strohmenger C. Prevalence of disability by cause. In: Demographic and health indicators - presentation and interpretation. Ottawa: Statistics Canada 82-543E, 1992:162-7.

36 Blanchard JF, Ludwig S, Wajda A, et al. Incidence and prevalence of diabetes in Manitoba, 1986-1991. Diabetes Care 1996;19: 807-11.

37 Sherman G. Canadian Congenital Anomalies Surveillance System (CCASS). Chronic Dis Can 1988:8:58-60.

38 Heale JD, Abernathy TJ, Kittle D. Using healthy life years (HeaLYs) to assess programming needs in a public health unit. Can J Public Health 2000;91:148-52.

39 Berthelot J-M, Roberge R, Cranswick K. Linking disability-adjusted life expectancy with health-adjusted life expectancy: Calculations for Canada. In: Egidi V, ed. Towards an integrated system of indicators to assess the health status of the population. Proceedings of the 9th workgroup meeting REVES, Rome, December 1996. Rome: ISTAT, 1999:27-53

40 Manuel DG, Goel V, Williams II, et al. Health-adjusted life expectancy at the local level in ontario. Chron Dis Can 2000;21:73-80.

\begin{tabular}{|c|c|c|c|c|c|}
\hline Value & Disease grouping & $\begin{array}{l}\text { ICD } 9 \text { codes (excluding V } \\
\text { codes) }\end{array}$ & $\begin{array}{l}\text { ICD9 V codes (included in } \\
\text { NPHS96-97/OHSII) }\end{array}$ & $\begin{array}{l}\text { NPHS-specific V } \\
\text { codes }\end{array}$ & $\begin{array}{l}\text { Chronic conditions (from } \\
\text { NPHS96-97/OHSII) }\end{array}$ \\
\hline 1 & $\begin{array}{l}\text { Ischaemic and other heart } \\
\text { disease }\end{array}$ & $\begin{array}{l}390-398 ; 410-414 ; \\
415-429 ;\end{array}$ & $\begin{array}{l}\text { V151, V421, V433, V450, } \\
\text { V472, V533 }\end{array}$ & & heart disease (ccc6_1l); \\
\hline 2 & $\begin{array}{l}\text { Cerebrovascular disease, } \\
\text { hypertensive disease and } \\
\text { other circulatory disorders }\end{array}$ & $\begin{array}{l}401-405 ; 430-438 \\
440-448 ; 450-459\end{array}$ & & & $\begin{array}{l}\text { high blood pressure }\left(\operatorname{ccc} 6 \_1 f\right) \\
\text { stroke (ccc6_lo); }\end{array}$ \\
\hline 3 & $\begin{array}{l}\text { Cancer (excluding benign } \\
\text { neoplasms) }\end{array}$ & 140-209; 230-239; & V581 & & cancer $\left(\mathrm{ccc}_{-} \_1 \mathrm{~m}\right)$; \\
\hline 4 & Diabetes mellitus & 250 & & & diabetes $($ ccc6_1j); \\
\hline 5 & $\begin{array}{l}\text { Diseases of the respiratory } \\
\text { system }\end{array}$ & $460-519$ & & & $\begin{array}{l}\text { asthma (ccc6_1c); } \\
\text { chronic bronchitis/emphysema } \\
\text { (ccc6_1h); } \\
\text { sinusitis (ccc6_li); }\end{array}$ \\
\hline 6 & $\begin{array}{l}\text { Diseases of the } \\
\text { musculoskeletal system }\end{array}$ & 710-739; & $\begin{array}{l}\text { V424, V436, V437, V495, } \\
\text { V537 }\end{array}$ & $\begin{array}{l}\text { VAOO-VU17 and } \\
\text { rac6_5 } 5=>5\end{array}$ & $\begin{array}{l}\text { arthritis/rheumatism }\left(\operatorname{ccc} 6 \_1 d\right) \text {; } \\
\text { back problems (ccc6_le); }\end{array}$ \\
\hline 7 & $\begin{array}{l}\text { Mental disorders (including } \\
\text { suicide) }\end{array}$ & 290-319; E950-959; & $\begin{array}{l}\text { V401, V402, V409, V611, } \\
\text { V623, V628 }\end{array}$ & & depression $(\mathrm{mhc} 6 \mathrm{dp}=>0.90)$ \\
\hline 8 & Accidents and injuries & $\begin{array}{l}\text { 800-999; or E800-E949; } \\
\text { E960-E999; }\end{array}$ & & $\begin{array}{l}\text { VAO0-VU17 and } \\
\text { rac6_5 } 5=<4\end{array}$ & \\
\hline 9 & $\begin{array}{l}\text { Diseases of the digestive and } \\
\text { genitourinary systems }\end{array}$ & $520-579 ;$ 580-629; & $\begin{array}{l}\text { V420, V442, V443, V451, } \\
\text { V473, V536, V568 }\end{array}$ & & $\begin{array}{l}\text { stomach or intestinal ulcers } \\
(\operatorname{ccc} 6 \text { _ln); } \\
\text { urinary incontinence }(\operatorname{ccc} 6 \text { _lp); } \\
\text { Crohn's or colitis }(\operatorname{ccc} 6) 1 \mathrm{q}) \text {; }\end{array}$ \\
\hline 10 & $\begin{array}{l}\text { Diseases of the nervous } \\
\text { system and sense organs }\end{array}$ & 320-389; & $\begin{array}{l}\text { V410, V411, V412, V413, } \\
\text { V414, V415, V425, V430, } \\
\text { V438, V532 }\end{array}$ & & $\begin{array}{l}\text { migraine (ccc6_lg); } \\
\text { epilepsy }\left(\operatorname{ccc} 6 \_1 \mathrm{k}\right) ; \\
\text { Alzheimer's }\left(\mathrm{ccc} 6 \_1 \mathrm{r}\right) \\
\text { cataracts }\left(\mathrm{ccc} 6 \_1 \mathrm{~s}\right) ; \\
\text { glaucoma (ccc6_lt); }\end{array}$ \\
\hline 11 & All other causes & $\begin{array}{l}\text { All Others: 001-139; } \\
\text { 210-229; 240-249; } \\
\text { 251-289; 630-709; } \\
\text { 740-799; }\end{array}$ & $\begin{array}{l}\text { V222, V434, V458, V534, } \\
\text { V538, V660 }\end{array}$ & & $\begin{array}{l}\text { food allergies (ccc6_la); } \\
\text { other allergies }\left(\operatorname{ccc} 6 \_1 \mathrm{~b}\right) ; \\
\text { thyroid problems }\left(\operatorname{ccc} 6 \_1 \mathrm{u}\right) \text {; } \\
\text { other (ccc6_lv); }\end{array}$ \\
\hline
\end{tabular}




\section{APPENDIX 2 HEALTH UTILITIES INDEX MARK III: HEALTH STATUS CLASSIFICATION SYSTEM ${ }^{40}$}

Please visit the journal web site (www.jech.com) to see appendix 2 .

\section{APPENDIX 3 EQUATIONS USED IN CALCULATING CAUSE DELETED HUI ESTIMATES}

\section{Equation 1}

The general formula for cause deleted mean HUI is:

$m H U I_{C D}=\frac{m H U I_{T}-\left(m H U I_{C} \times P_{C}\right)}{1-P_{C}}$

where:

$m H U I_{C D}=$ Cause deleted mean HUI

$m H U I_{T}=$ Overall mean HUI

$m H U I_{c}=$ Cause specific mean HUI

$P_{C}=$ Proportion reporting the specific cause

\section{Equation 2}

Cause deleted mean HUI estimates were calculated from the regression coefficients using the following formula:

$m H U I_{C D}=m H U I_{T}-\left(\beta_{C} \times P_{C}\right)$

where:

$m H U I_{C D}=$ Cause deleted mean HUI

$m H U I_{T}=$ Overall mean HUI

$\beta_{c}=$ the $\beta$ coefficient for the particular cause

$P_{C}=$ the proportion reporting the particular cause

Equation 3

With two groups as in this study, the overall causedeleted mean HUI becomes the sum of the two individual means, weighted by their proportions. The formula becomes:

$$
\begin{aligned}
m H U I_{C D T}= & \left(m H U I_{C D G 1} \times P_{G 1}\right) \\
& +\left(m H U I_{C D G 2} \times P_{G 2}\right)
\end{aligned}
$$

where:

$m H U I_{C D T}=$ Overall cause deleted mean HUI

$m H U I_{C D G I}=$ Cause deleted mean HUI for the first group $m H U I_{C D G 2}=$ Cause deleted mean HUI for the second group $P_{G I}=$ Proportion of the population in the first group $P_{G 2}=$ Proportion of the population in the second group 